\title{
Protein S100 as outcome predictor after out-of-hospital cardiac arrest and targeted temperature management at $33^{\circ} \mathrm{C}$ and $36{ }^{\circ} \mathrm{C}$
}

Pascal Stammet ${ }^{1 *}$ D, Josef Dankiewicz ${ }^{2}$, Niklas Nielsen ${ }^{3}$, François Fays ${ }^{4}$, Olivier Collignon ${ }^{4}$, Christian Hassager $^{5}$, Michael Wanscher ${ }^{6}$, Johan Undèn ${ }^{7}$, Jorn Wetterslev ${ }^{8}$, Tommaso Pellis $^{9}$, Anders Aneman $^{10}$, Jan Hovdenes ${ }^{11}$, Matt P. Wise ${ }^{12}$, Georges Gilson ${ }^{13}$, David Erlinge ${ }^{2}$, Janneke Horn ${ }^{14}$, Tobias Cronberg ${ }^{15}$, Michael Kuiper ${ }^{16}$, Jesper Kjaergaard ${ }^{5}$, Yvan Gasche ${ }^{17}$, Yvan Devaux ${ }^{18}$, Hans Friberg ${ }^{19}$ and Target Temperature Management after Out-of-Hospital Cardiac Arrest (TTM) trial investigators

\begin{abstract}
Background: We aimed to investigate the diagnostic performance of S100 as an outcome predictor after out-of-hospital cardiac arrest (OHCA) and the potential influence of two target temperatures $\left(33^{\circ} \mathrm{C}\right.$ and $\left.36^{\circ} \mathrm{C}\right)$ on serum levels of S100.

Methods: This is a substudy of the Target Temperature Management after Out-of-Hospital Cardiac Arrest (TTM) trial. Serum levels of S100 were measured a posteriori in a core laboratory in samples collected at 24, 48, and $72 \mathrm{~h}$ after OHCA. Outcome at 6 months was assessed using the Cerebral Performance Categories Scale (CPC 1-2 = good outcome, CPC 3-5 = poor outcome).

Results: We included 687 patients from 29 sites in Europe. Median $\$ 100$ values were higher in patients with a poor outcome at 24, 48, and 72 h: 0.19 (IQR 0.10-0.49) versus 0.08 (IQR 0.06-0.11) $\mu \mathrm{g} / \mathrm{ml}, 0.16$ (IQR 0.10-0.44) versus 0.07 (IQR 0.06-0.11) $\mu \mathrm{g} / \mathrm{L}$, and 0.13 (IQR $0.08-0.26)$ versus 0.06 (IQR $0.05-0.09) \mu \mathrm{g} / \mathrm{L}(p<0.001)$, respectively. The ability to predict outcome was best at $24 \mathrm{~h}$ with an AUC of 0.80 (95\% Cl 0.77-0.83). S100 values were higher at 24 and $72 \mathrm{~h}$ in the $33^{\circ} \mathrm{C}$ group than in the $36^{\circ} \mathrm{C}$ group (0.12 [0.07-0.22] versus 0.10 [0.07-0.21] $\mu \mathrm{g} / \mathrm{L}$ and 0.09 [0.06-0.17] versus 0.08 [0.05-0.10], respectively) $(p<0.02) . \ln$ multivariable analyses including baseline variables and the allocated target temperature, the addition of S100 improved the AUC from 0.80 to 0.84 (95\% Cl 0.81-0.87) $(p<0.001)$, but S100 was not an independent outcome predictor. Adding S100 to the same model including neuron-specific enolase (NSE) did not further improve the AUC.

Conclusions: The allocated target temperature did not affect S100 to a clinically relevant degree. High S100 values are predictive of poor outcome but do not add value to present prognostication models with or without NSE. S100 measured at $24 \mathrm{~h}$ and afterward is of limited value in clinical outcome prediction after OHCA.
\end{abstract}

Trial registration: ClinicalTrials.gov identifier: NCT01020916. Registered on 25 November 2009.

Keywords: Biomarker, S100, Prognosis, Neuroprognostication, Cerebral performance

\footnotetext{
*Correspondence: stammet.pascal@chl.lu

${ }^{1}$ Department of Anesthesia and Intensive Care Medicine, Centre Hospitalier

de Luxembourg, 4, rue Barblé, L-1210 Luxembourg, Luxembourg

Full list of author information is available at the end of the article
} 


\section{Background}

Mortality in comatose out-of-hospital cardiac arrest (OHCA) patients admitted to an intensive care unit (ICU) is around $50 \%$. Whereas initial ICU mortality is caused by hemodynamic failure in the majority of cases, later morbidity and mortality are due mainly to hypoxic brain damage $[1,2]$. Withdrawal of life-sustaining therapies (WLST) based on presumed poor neurological prognosis is the predominant cause of death $[2,3]$. To better guide therapy and to support decisions on WLST, there is a need for early and accurate outcome prediction tools in this severely ill population.

The $\mathrm{S} 100$ protein, a $21 \mathrm{kDa}$ intracellular calciumbinding dimer, is implicated in neuronal differentiation, proliferation, and apoptosis [4]. Many subtypes of the S100 protein are known, but the most studied in humans are the brain-specific homodimers $\mathrm{A} 1 \mathrm{~B}(\alpha \beta)$ and $\mathrm{BB}(\beta \beta)$ $[5,6]$. S100 is a biomarker candidate for outcome prediction after cardiac arrest (CA) [7, 8], but previous small studies yielded a wide range of cutoff values for a poor outcome, and current guidelines do not advocate its use [9]. S100 is present mainly in white matter, predominantly in astroglial cells, in contrast to neuron-specific enolase (NSE), which is found principally in neurons and neuroendocrine cells [10]. S100 is also commonly present in extracerebral tissues $[11,12]$. The Target Temperature Management after Out-of-Hospital Cardiac Arrest (TTM) trial, a multicenter clinical trial that randomized 939 patients to targeted temperature management of $33{ }^{\circ} \mathrm{C}$ or $36{ }^{\circ} \mathrm{C}$, provides an opportunity to investigate the role of S100 as a prognostic marker after OHCA [13].

\section{Goals of this study}

The aim of this study was to investigate the diagnostic accuracy of S100 as an outcome predictor after CA and whether serial S100 samples conferred an added value to recommended prognostication models [9]. Another aim was to investigate the potential influence of two target temperatures $\left(33^{\circ} \mathrm{C}\right.$ and $\left.36{ }^{\circ} \mathrm{C}\right)$ on $\mathrm{S} 100$ release curves.

\section{Methods}

\section{Study design and setting}

All patients included in this study were part of the TTM trial (from November 2010 to July 2013; ClinicalTrials.gov identifier NCT01020916), in which two target temperature regimens were compared in adult unconscious patients admitted to an ICU after an OHCA of a presumed cardiac cause [13]. The TTM trial design, statistical analysis plan, and main results were published previously [13-15]. Patients were randomized to a target temperature of $33{ }^{\circ} \mathrm{C}$ or $36^{\circ} \mathrm{C}$. Twenty-eight hours after the start of the intervention, rewarming to $37{ }^{\circ} \mathrm{C}$ was started at a maximum speed of $0.5{ }^{\circ} \mathrm{C} / \mathrm{h}$. The steering committee approved this predefined substudy before trial completion and before starting analysis of S100.

\section{Study population}

All patients included at sites participating in the biobank substudy of the TTM trial were included. Seven TTM trial sites did not participate in the biobank substudy, owing to logistical issues and legal concerns. Data of patients who died before the scheduled blood sampling and of patients with incomplete sampling were treated as missing.

\section{Sampling and measurements}

After return of spontaneous circulation (ROSC), serum blood samples were collected at 24, 48, and $72 \mathrm{~h}$. All samples were preanalytically processed at the different sites, aliquoted, and frozen at $-80{ }^{\circ} \mathrm{C}$ before shipment to the Integrated Biobank of Luxembourg. S100 determination was performed 6 months after trial completion at the clinical biology laboratory of the Centre Hospitalier de Luxembourg, and the measurements were therefore not available to the treating physician during the trial.

Determination of S100 (S100A1B and S100BB) was performed using a cobas e601 line with an electrochemiluminescence immunoassay kit (Roche Diagnostics, Rotkreuz, Switzerland). The measurement range extended from 0.005 to $39 \mu \mathrm{g} / \mathrm{L}$. Samples with values above the measurement range had to be diluted accordingly. Functional sensitivity was set at $0.02 \mu \mathrm{g} / \mathrm{L}$, and expected normal values were $<0.105 \mu \mathrm{g} / \mathrm{L}$. In our laboratory, between-run precision at concentrations of 0.18 and $2.33 \mu \mathrm{g} / \mathrm{L}$ was $2.6 \%$ and $3.6 \%$, respectively.

\section{Outcomes}

We aimed to investigate S100 as a predictor of death and cerebral performance after OHCA in both temperature groups. We defined high $\mathrm{S} 100$ cutoff values as having a false-positive rate (FPR) for a poor outcome of $\leq 5 \%$.

The primary outcome in this study was neurological function at 6 months, dichotomized into good or poor outcome according to the Cerebral Performance Categories Scale (CPC) [16]. The CPC score classifies patients into five categories: CPC 1 (no neurological disability), CPC 2 (minor neurological deficit), CPC 3 (severe neurological impairment, dependent in everyday life), CPC 4 (coma), and CPC 5 (death). CPC scores of 1 or 2 were considered a good outcome, whereas CPC scores of 3-5 were considered a poor outcome. Neurological prognostication as well as WLST were standardized and reported according to the trial protocol [13-15].

\section{Statistical analysis}

All group comparisons of continuous measures were performed using Wilcoxon's test, whereas the chi-square or Fisher's exact test was used to assess categorical data. Concentrations of S100 were compared over time using the Wilcoxon signed-rank test. 
Univariate analysis consisted of plotting ROC curves of S100 and computing the AUC for each time point. Because there is no established cutoff value for S100 to predict outcome, we took a broad approach in evaluating potential cutoff values. Predictive cutoffs were determined by maximizing the Youden index and by reporting 95-100\% specificity for a poor neurological outcome. Multivariable analyses were performed by adding S100 measurements first to a logistic clinical model of CPC adjusted for targeted temperature and for the patients' characteristics (target temperature, age, time to ROSC, lactate level on admission, sex, bystander CPR, first monitored rhythm, ROSC after bystander CPR and circulatory shock on admission), and then to the same model including both those variables and NSE measurements at 24, 48, and $72 \mathrm{~h}$. Bootstrap internal validation and multiple imputations were further performed to correct sensitivity and specificity, respectively, for optimism and to account for missing data. The continuous Net Reclassification Index (NRI) and the integrated discrimination improvement (IDI) were computed to evaluate the added predictive value of S100. DeLong's test was used to compare AUCs computed without multiple imputations, and a likelihood ratio test was performed to compare the fit of the models. Differences in survival until the end of the trial were assessed using Kaplan-Meier curves and the log-rank test.

$\mathrm{R}$ software (version 2.15.2, http://www.r-project.org/; R Foundation for Statistical Computing, Vienna, Austria) with the packages ROCR, pROC, Hmisc, and rms was used to perform the computations. A $p$ value $<0.05$ was considered statistically significant.

\section{Results}

\section{Characteristics of study subjects}

The TTM trial researchers investigated 939 patients, who had no difference in mortality or neurological function between the $33{ }^{\circ} \mathrm{C}$ and the $36^{\circ} \mathrm{C}$ groups [13]. Overall, 700 consecutive patients from 29 different sites participated in the biomarker substudy (Fig. 1a). A total of 1843 serum samples from 687 different patients were analyzed (Fig. 1b). The main patient characteristics are shown in Table 1 . There were no marked differences between our study population

\section{a}

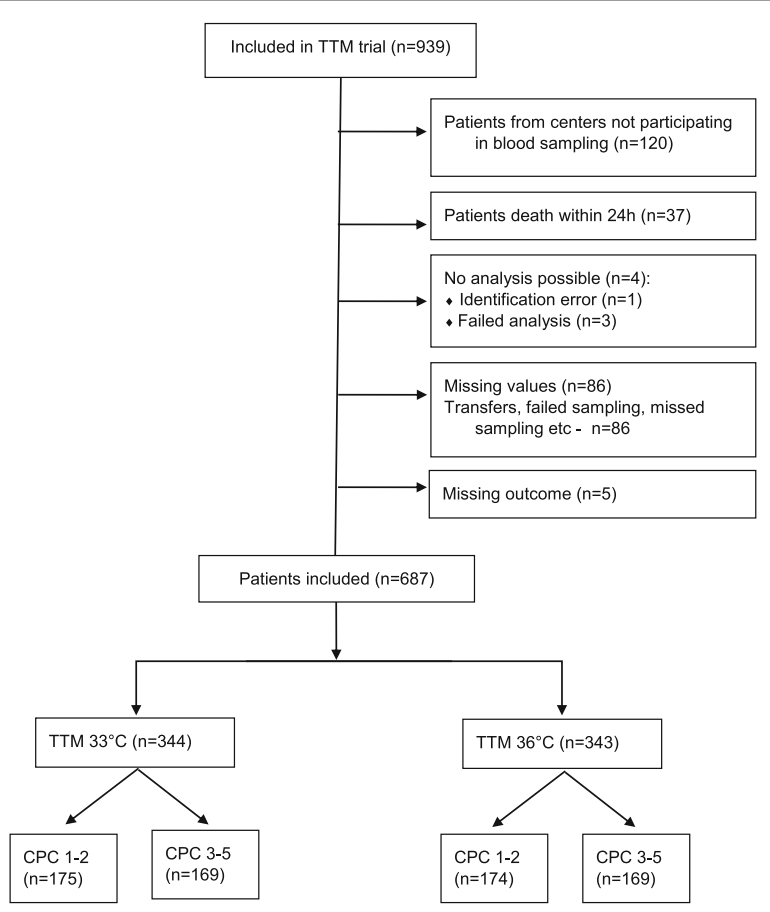

b

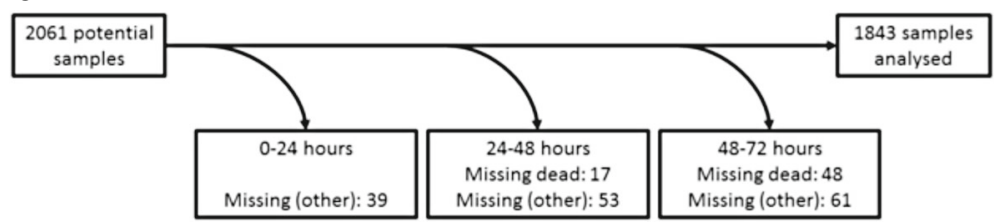

Fig. 1 Study flowchart. Number of patients enrolled in the TTM trial and included in this substudy a; Number of samples included in this study and reasons for eliminating serum samples from analysis b. TTM Target Temperature Management after Out-of-Hospital Cardiac Arrest trial, CPC Cerebral Performance Categories Scale 
Table 1 Main demographic and Utstein data

\begin{tabular}{lll}
\hline & $33^{\circ} \mathrm{C}(n=344)$ & $36^{\circ} \mathrm{C}(n=343)$ \\
\hline Male sex, $n(\%)$ & $292(83)$ & $273(79)$ \\
Age, mean (SD) & $64.2(11.8)$ & $63.4(12.9)$ \\
First monitored rhythm, $n(\%):$ & & \\
$\quad$ Asystole or PEA & $67(19)$ & $64(18)$ \\
$\quad$ Non perfusing VT or VF & $273(77)$ & $272(78)$ \\
$\quad$ ROSC after bystander defibrillation & $6(2)$ & $3(1)$ \\
$\quad$ Unknown initial rhythm & $6(2)$ & $8(2)$ \\
Time from CA to ROSC, mean (SD) & $30.5(21.5)$ & $31.1(23.8)$ \\
Lactate, mmol/L, mean (SD) & $6.6(4.4)$ & $6.6(4.4)$ \\
Shock on admission, $n(\%)$ & $45(13)$ & $43(12)$
\end{tabular}

Abbreviations: CA Cardiac arrest, CPR Cardiopulmonary resuscitation, $P E A$ Pulseless electrical activity, ROSC Return of spontaneous circulation, VF Ventricular fibrillation, $V T$ Ventricular tachycardia

Values are mean and SD or $n(\%)$ and the main TTM trial population or in neurological outcome between temperature groups (data not shown).

\section{S100 values by outcome group}

Median S100 values were significantly higher in patients with poor versus good outcomes at 24,48 , and $72 \mathrm{~h}$ respectively: 0.19 (IQR 0.10-0.49) versus 0.08 (IQR 0.06-0.11) $\mu \mathrm{g} /$ $\mathrm{ml}, 0.16$ (IQR 0.10-0.44) versus 0.07 (IQR 0.06-0.11) $\mu \mathrm{g} / \mathrm{L}$, and 0.13 (IQR 0.08-0.26) versus 0.06 (IQR 0.05-0.09) $\mu \mathrm{g} / \mathrm{L}$ (all $p<0.001$ ). There was a significant decrease in serum levels in both outcome groups over time (Fig. 2).

\section{Influence of temperature on $\mathbf{S 1 0 0}$}

S100 values were significantly higher at 24 and $72 \mathrm{~h}$ in the $33{ }^{\circ} \mathrm{C}$ group than in the $36{ }^{\circ} \mathrm{C}$ group $(0.12$ [0.07$0.22]$ versus $0.10[0.07-0.21] \mu \mathrm{g} / \mathrm{L}$ and 0.09 [0.06-0.17] versus 0.08 [0.05-0.10] at 24 and $72 \mathrm{~h}$, respectively; $p<$ $0.02)$. No significant difference was found at $48 \mathrm{~h}$. When comparing the groups by their outcome, we found significantly higher median values in the good outcome groups in the $33{ }^{\circ} \mathrm{C}$ arm than in the $36{ }^{\circ} \mathrm{C}$ arm: 0.08 $(0.07-0.12)$ versus $0.07(0.05-0.10) \mu \mathrm{g} / \mathrm{L}(p=0.004), 0.08$ $(0.06-0.12)$ versus $0.07(0.05-0.10) \mu \mathrm{g} / \mathrm{L}(p=0.002)$, and

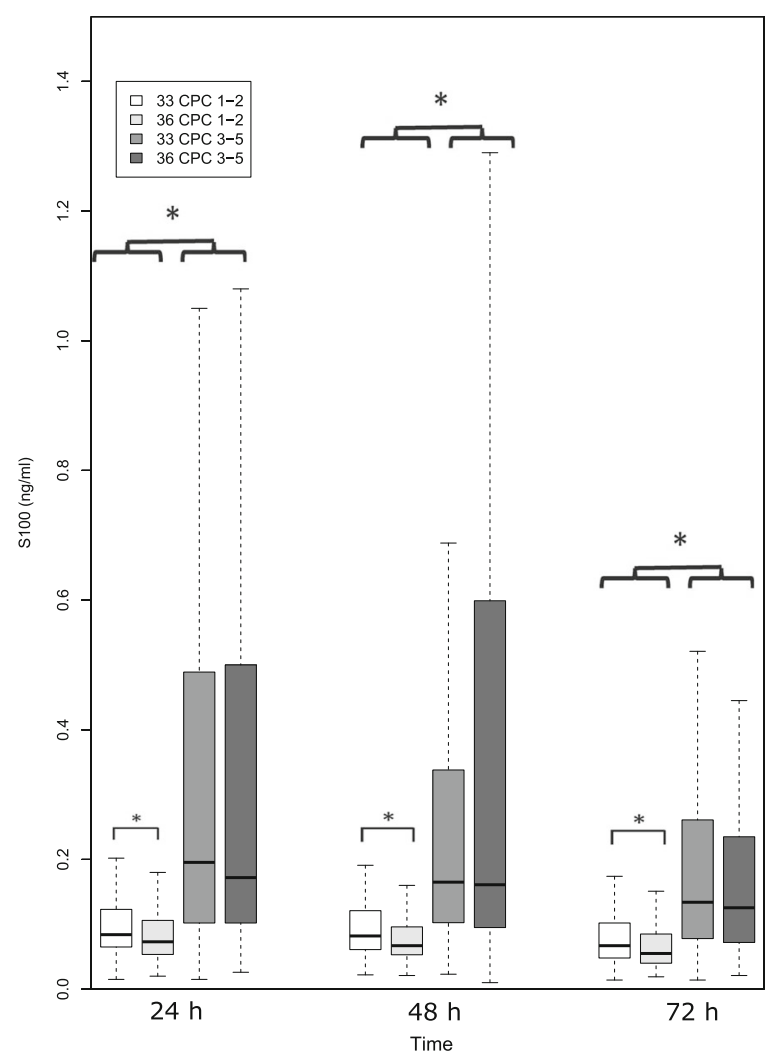

Fig. 2 S100 time course. Box plots of S100 over the first $72 \mathrm{~h}$ after return of spontaneous circulation. Data are presented as median, quartile 1, quartile 3, and lower fence (i.e., lowest value above [quartile 1-1.5 \{quartile3 - quartile1\}]) and upper fence (i.e., greater value below [quartile $3+1.5$ \{quartile3 quartile1\}]). A statistical difference was found only for S100 values of patients with good outcomes, with higher values in the $33^{\circ} \mathrm{C}$ group and between good and poor outcome groups. ${ }^{*} p<0.05$. CPC Cerebral Performance Categories Scale 
$0.07(0.05-0.10)$ versus $0.06(0.04-0.08) \mu \mathrm{g} / \mathrm{L}(p=0.002)$ at 24,48 , and $72 \mathrm{~h}$, respectively. There was no significant difference in levels of S100 between temperature groups in the poor outcome groups.

\section{Predictive capacity of $\mathrm{S} 100$}

The capacity of S100 to predict CPC score at 6 months was first determined using ROC curves (Fig. $3 \mathrm{a}-\mathrm{c}$ ). The best performance of $\mathrm{S} 100$ was at $24 \mathrm{~h}$, with AUCs of 0.78 (95\% CI $0.73-0.83$ ) for patients treated at $33{ }^{\circ} \mathrm{C}$ and $0.82(95 \% \mathrm{CI} 0.77-0.87)$ for patients treated at $36{ }^{\circ} \mathrm{C}$, as well as an AUC of 0.80 (95\% CI 0.77-0.83) when both temperature groups were combined. At $48 \mathrm{~h}$ and $72 \mathrm{~h}$, AUCs were lower. AUCs did not differ significantly between temperature groups at any time point $(p>0.11)$.

Cutoff values with FPRs ranging from $0(100 \%$ specificity) to $5 \%$, as well as with a maximized Youden index for all patients, are presented in Table 2. Cutoff values for both temperatures groups were not markedly different, except for those with an FPR of 0 (data not shown).

Survival was associated with S100 levels and was significantly lower in groups with higher S100 levels as defined by quartiles (Fig. 4). At each time point, S100 was a significant predictor of survival in both temperature groups $(p<0.001)$.

\section{Multivariable analysis}

In multivariable analysis including the allocated target temperature and baseline variables (age, sex, bystander cardiopulmonary resuscitation, first monitored rhythm, time to ROSC, lactate levels on admission, and circulatory shock), all variables except target temperature, gender and shock on admission were independent neurological outcome predictors (AUC 0.80, 95\% CI: 0.76-0.83, sensitivity 0.73 , specificity 0.76 ) (data not shown). When serial S100 values were added to this model, none of the three S100measurements was an independent outcome predictor, (Table 3) but the AUC of the model including serial samples improved to 0.84 (95\%CI: $0.81-0.87$, sensitivity 0.75 , specificity 0.81 , DeLong test $p<0.001$, likelihood test $p<$ 0.001 ). Adding S100 improved the reclassification of patients significantly as demonstrated by continuous NRI $(0.53, p<0.001)$ and IDI $(0.08, p<0.001)$. When adding serial S100 values to another, previously published model including the same clinical characteristics and NSE values at the 3 time-points (AUC 0.92, 95\%CI: 0.90-0.94) [17], S100 did not further improve the AUC $(0.92,95 \%$ CI: $0.90-0.94$, sensitivity 0.81 , specificity 0.92 , DeLong test $p=0.13$, likelihood test $p=0.08$ ) (Table 4 ).

We thereafter repeated the same multivariable analysis without multiple imputations and in unconscious patients

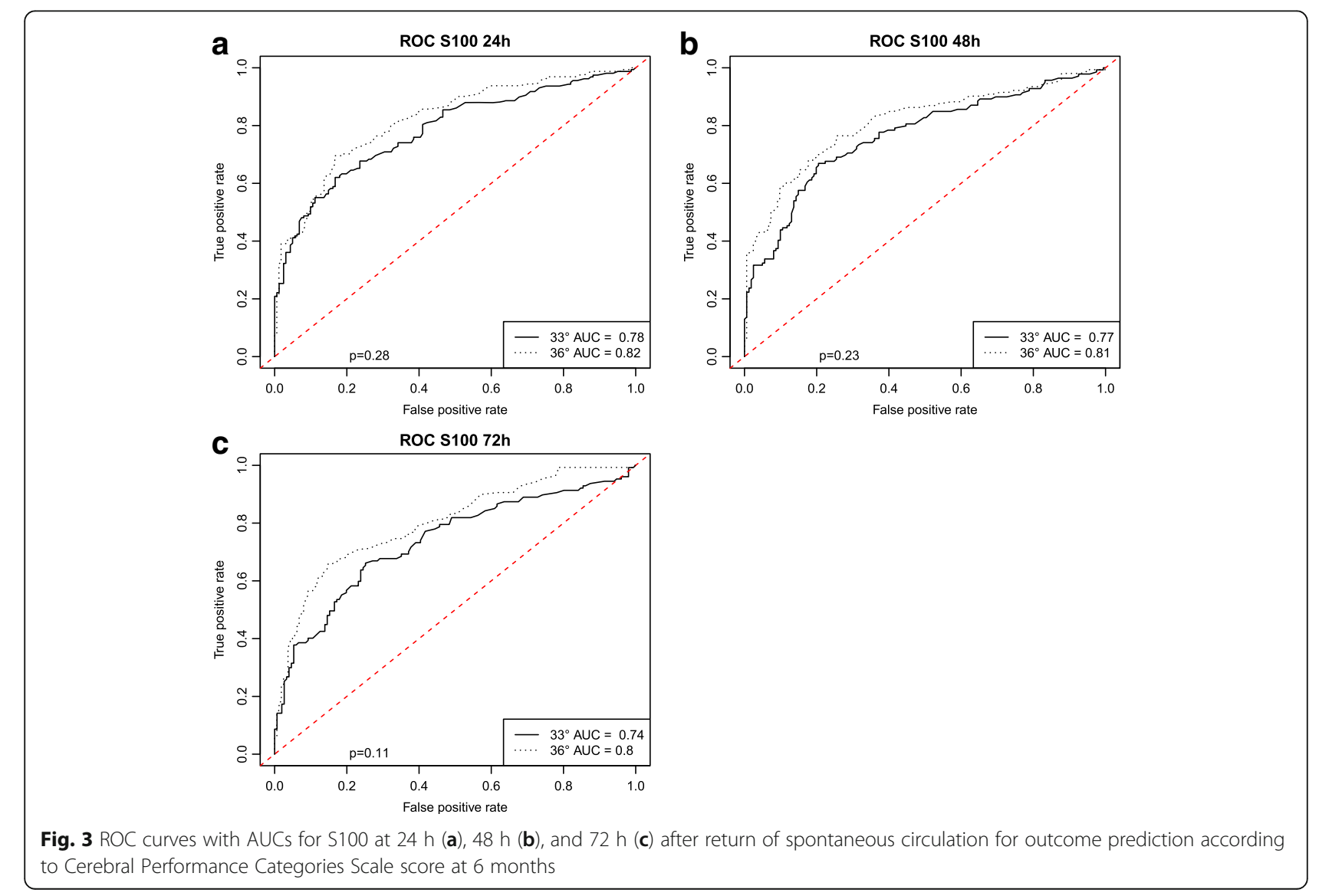


Table 2 S100 cutoff values

\begin{tabular}{|c|c|c|c|c|c|c|}
\hline Time point & & Cutoff $(\mu \mathrm{g} / \mathrm{L})$ & Sensitivity & $95 \% \mathrm{Cl}$ & Specificity & $95 \% \mathrm{Cl}$ \\
\hline & S100 Youden & 0.12 & 0.68 & $0.63-0.73$ & 0.77 & $0.73-0.82$ \\
\hline & S100_5 & 0.25 & 0.41 & $0.35-0.46$ & 0.95 & $0.93-0.97$ \\
\hline & S100_4 & 0.28 & 0.40 & $0.34-0.45$ & 0.96 & $0.94-0.98$ \\
\hline \multirow[t]{7}{*}{$24 \mathrm{~h}$} & S100_3 & 0.32 & 0.35 & $0.30-0.40$ & 0.97 & $0.95-0.99$ \\
\hline & S100_2 & 0.36 & 0.32 & $0.26-0.37$ & 0.98 & $0.96-0.99$ \\
\hline & S100_1 & 0.72 & 0.22 & $0.17-0.26$ & 0.99 & $0.97-1.00$ \\
\hline & S100_0 & 2.59 & 0.10 & $0.07-0.13$ & 1.00 & $0.99-1.00$ \\
\hline & S100 Youden & 0.13 & 0.63 & $0.57-0.68$ & 0.82 & $0.78-0.86$ \\
\hline & S100_5 & 0.25 & 0.36 & $0.30-0.41$ & 0.95 & $0.93-0.98$ \\
\hline & S100_4 & 0.25 & 0.36 & $0.30-0.41$ & 0.96 & $0.94-0.98$ \\
\hline \multirow[t]{7}{*}{$48 \mathrm{~h}$} & S100_3 & 0.27 & 0.34 & $0.28-0.39$ & 0.97 & $0.95-0.99$ \\
\hline & S100_2 & 0.28 & 0.34 & $0.28-0.39$ & 0.98 & $0.96-0.99$ \\
\hline & S100_1 & 0.36 & 0.28 & $0.23-0.34$ & 0.99 & $0.97-0.99$ \\
\hline & S100_0 & 3.67 & 0.05 & $0.03-0.08$ & 1.00 & $0.99-1.00$ \\
\hline & S100 Youden & 0.10 & 0.65 & $0.59-0.71$ & 0.80 & $0.75-0.84$ \\
\hline & S100_5 & 0.19 & 0.35 & $0.29-0.40$ & 0.95 & $0.92-0.97$ \\
\hline & S100_4 & 0.23 & 0.29 & $0.24-0.35$ & 0.96 & $0.94-0.98$ \\
\hline \multirow[t]{4}{*}{$72 \mathrm{~h}$} & S100_3 & 0.26 & 0.25 & $0.20-0.30$ & 0.97 & $0.95-0.99$ \\
\hline & S100_2 & 0.35 & 0.20 & $0.15-0.24$ & 0.98 & $0.96-0.99$ \\
\hline & S100_1 & 0.52 & 0.15 & $0.11-0.19$ & 0.99 & $0.97-0.99$ \\
\hline & S100_0 & 1.83 & 0.05 & $0.02-0.08$ & 1.00 & $0.98-1.00$ \\
\hline
\end{tabular}

S100 cutoff values for poor outcome prediction, pooled data for target temperature

S100 Youden indicates S100 cutoff with the compromise of the best sensitivity and specificity (maximized Youden index). The number following S100 refers to the false-positive rate. Sensitivity and specificity are corrected by bootstrap internal validation

on day 3, with and without the addition of NSE. In each analysis, S100 was not an independent outcome predictor.

\section{Discussion}

In this substudy of a large international trial, the use of S100 for outcome prediction after OHCA was assessed. S100 values were higher in patients with poor outcomes at all time points, with the best capacity for S100 to predict outcome being at $24 \mathrm{~h}$. In multivariable analysis, S100 measurements at 24, 48, and $72 \mathrm{~h}$ were not significant predictors of outcome. The joint effect of the three measurements, however, improved the AUC, NRI, and IDI of a predictive model that included established clinical characteristics associated with outcome.

In previous, smaller studies, researchers compared S100 in two target temperature groups and could not detect a significant influence of temperature on S100 levels $[18,19]$. In this study, S100 values were higher at 24 and $72 \mathrm{~h}$ in the $33{ }^{\circ} \mathrm{C}$ group than in the $36{ }^{\circ} \mathrm{C}$ group, which was explained by higher S100 values among patients with good outcomes in the $33{ }^{\circ} \mathrm{C}$ group. Because the intervention groups and their outcomes were very similar in all aspects other than the intervention temperature, we speculate that this difference might be related to the targeted temperature. In addition, the observed values among patients with good outcomes were well below the suggested cutoff levels for S100. Although we do not have a clear explanation for this result, we consider the finding to be of negligible clinical relevance.

S100 could distinguish patients with good and poor outcomes after OHCA because median values were higher in the poor outcome group, and this has been described in previous reports $[18,20-25]$. It is noteworthy that S100 values declined over time in both temperature groups and for both outcome groups, indicating an early peak of this biomarker, which might explain why the first sample (at $24 \mathrm{~h}$ after ROSC) showed the best results [26]. We did not collect blood samples before $24 \mathrm{~h}$ after ROSC, and higher levels prior to $24 \mathrm{~h}$ cannot be ruled out. However, a clear peak earlier than $24 \mathrm{~h}$ could not be determined in a previous study in which researchers investigated the kinetic profile of S100 [23]. Other studies have also confirmed a similar decline over time after $24 \mathrm{~h}$ in patients with good and poor outcomes $[22,25]$. The early release and subsequent decline may be explained by the short half-life of approximately $2 \mathrm{~h}$ in combination with a low molecular weight, allowing a rapid transition through the bloodbrain barrier [27]. This differentiates S100 from other 
s100 24h
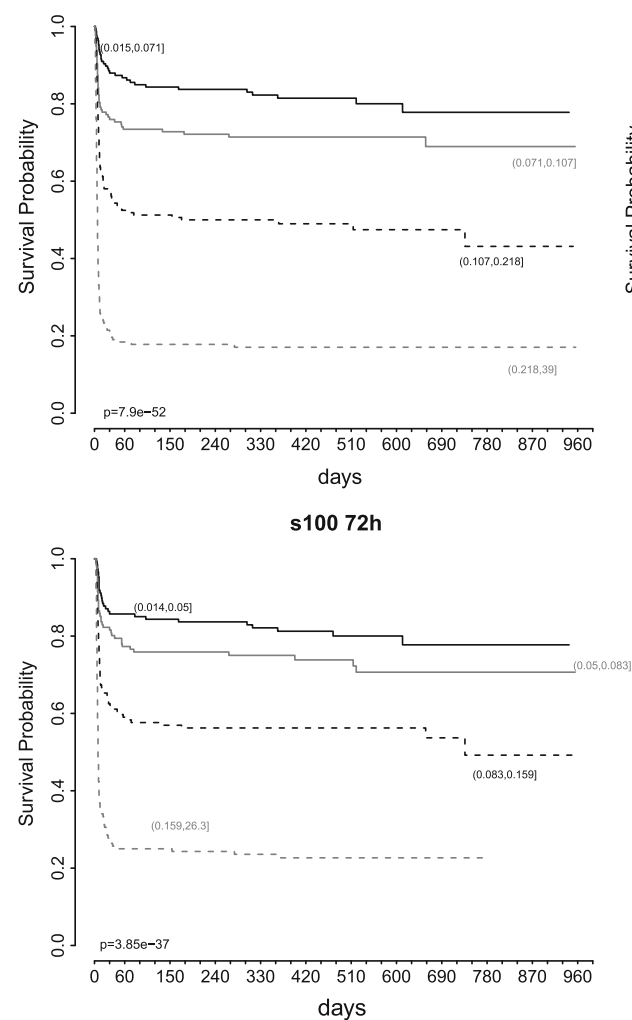

s100 48h

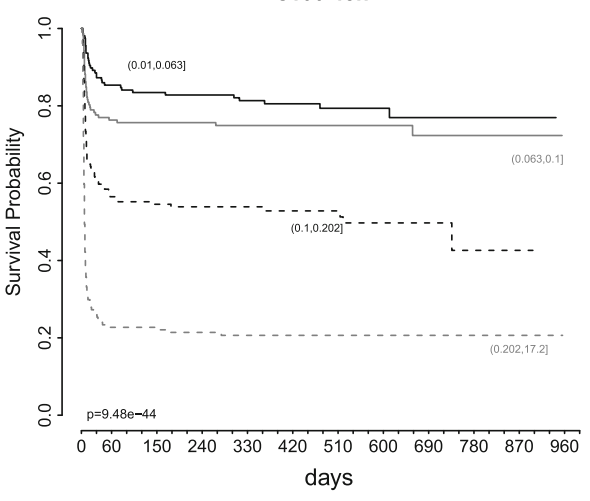

Fig. 4 Kaplan-Meier curves for prediction of survival at the end of the trial (primary endpoint of the Target Temperature Management after Out-of-Hospital

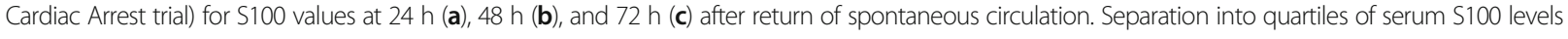

Table 3 Multivariable analysis with multiple imputation: clinical variables and $\mathbf{S 1 0 0}$

\begin{tabular}{|c|c|c|c|c|c|}
\hline \multirow[b]{2}{*}{ S100+ clinical } & \multirow[b]{2}{*}{ Effect } & \multirow[b]{2}{*}{ Odds ratio } & \multicolumn{2}{|l|}{$95 \% \mathrm{Cl}$} & \multirow[b]{2}{*}{$p$ Value } \\
\hline & & & Lower & Upper & \\
\hline Intercept & -3.670 & & 0.01 & 0.11 & $<0.001$ \\
\hline $\mathrm{S} 100$ at $24 \mathrm{~h}$ & 1.828 & 6.221 & 0.77 & 50.55 & 0.09 \\
\hline $\mathrm{S} 100$ at $48 \mathrm{~h}$ & 0.873 & 2.395 & 0.13 & 45.81 & 0.56 \\
\hline $\mathrm{S} 100$ at $72 \mathrm{~h}$ & 1.594 & 4.926 & 0.21 & 117.39 & 0.32 \\
\hline Target temperature & 0.085 & 1.089 & 0.75 & 1.59 & 0.66 \\
\hline Age & 0.062 & 1.064 & 1.05 & 1.08 & $<0.001$ \\
\hline Time CA to ROSC & 0.022 & 1.022 & 1.01 & 1.03 & $<0.001$ \\
\hline Lactate level on admission & -0.001 & 0.999 & 0.95 & 1.05 & 0.98 \\
\hline Sex & -0.271 & 0.762 & 0.47 & 1.24 & 0.27 \\
\hline Bystander CPR performed & -0.527 & 0.590 & 0.39 & 0.90 & 0.02 \\
\hline VTNF versus PEA/asystole & -1.431 & 0.239 & 0.13 & 0.43 & $<0.001$ \\
\hline $\begin{array}{l}\text { ROSC after bystander } \\
\text { defibrillation }\end{array}$ & -1.560 & 0.210 & 0.05 & 0.88 & 0.03 \\
\hline Shock on admission & 0.160 & 1.173 & 0.62 & 2.21 & 0.98 \\
\hline
\end{tabular}

Abbreviations: CA Cardiac arrest, CPR Cardiopulmonary resuscitation, $P E A$ Pulseless electrical activity, ROSC Return of spontaneous circulation, $V F$ Ventricular fibrillation, $V T$ Ventricular tachycardia biomarkers (e.g., NSE), where the kinetics between 24 and $72 \mathrm{~h}$ after CA are indicative of outcome [17]. The earlier peak of S100 and its relative strength over NSE and other biomarkers for outcome prediction at $24 \mathrm{~h}$ could potentially be of clinical use under certain circumstances, such as when prolonged care after rewarming might be considered unethical and several prognostic indicators point to a poor outcome. Another argument in favor of using S100 as an adjunct in prognostication after CA might be its availability in many centers, owing to its common use in the assessment of traumatic brain injury [28].

The cutoff values for S100 in this study are comparable with those described previously [7, 8, 25, 29]. Any differences might be due to different assays that might yield different values [20,22, 23], different outcome measures [29], and sample size [23]. As with other biomarkers, an absolute cutoff value with an FPR of 0 for poor outcome may be unrealistic and would limit its use. A more feasible approach might be to choose a higher FPR, which might be acceptable when used in combination with other prediction tools [9]. In this study, a cutoff with an FPR of $5 \%$ would correspond to an S100 serum level of $0.25 \mu \mathrm{g} / \mathrm{L}$ at $24 \mathrm{~h}$ after ROSC.

As with any other prognostication method, prediction should be based on a protocol including a holistic 
Table 4 Multivariable analysis with multiple imputation of clinical variables, S100, and neuron-specific enolase

\begin{tabular}{|c|c|c|c|c|c|}
\hline \multirow[b]{2}{*}{ Model S100 + NSE + clinical analysis } & \multirow[b]{2}{*}{ Effect } & \multirow[b]{2}{*}{ Odds ratio } & \multicolumn{2}{|l|}{$95 \% \mathrm{Cl}$} & \multirow[b]{2}{*}{$p$ Value } \\
\hline & & & Lower & Upper & \\
\hline Intercept & -6.480 & & 0.00 & 0.01 & $<0.001$ \\
\hline $\mathrm{S} 100$ at $24 \mathrm{~h}$ & 1.012 & 2.751 & 0.49 & 15.33 & 0.25 \\
\hline $\mathrm{S} 100$ at $48 \mathrm{~h}$ & -1.808 & 0.164 & 0.00 & 6.89 & 0.34 \\
\hline $\mathrm{S} 100$ at $72 \mathrm{~h}$ & 2.284 & 9.820 & 0.24 & 401.61 & 0.23 \\
\hline NSE at $24 \mathrm{~h}$ & -0.041 & 0.960 & 0.93 & 0.98 & $<0.001$ \\
\hline NSE at $48 \mathrm{~h}$ & 0.065 & 1.068 & 1.04 & 1.10 & $<0.001$ \\
\hline NSE at $72 \mathrm{~h}$ & 0.026 & 1.026 & 1.00 & 1.05 & 0.02 \\
\hline Target temperature & 0.187 & 1.206 & 0.76 & 1.91 & 0.43 \\
\hline Age & 0.091 & 1.095 & 1.07 & 1.12 & $<0.001$ \\
\hline Time CA to ROSC & 0.009 & 1.010 & 1.00 & 1.02 & 0.17 \\
\hline Lactate level on admission & 0.003 & 1.003 & 0.94 & 1.07 & 0.93 \\
\hline Sex & -0.400 & 0.671 & 0.38 & 1.20 & 0.18 \\
\hline Bystander CPR performed & -0.706 & 0.494 & 0.29 & 0.83 & 0.01 \\
\hline VTNF versus PEA/asystole & -1.062 & 0.346 & 0.17 & 0.72 & $<0.001$ \\
\hline ROSC after bystander defibrillation & -0.926 & 0.396 & 0.07 & 2.11 & 0.28 \\
\hline Shock on admission & 0.356 & 1.428 & 0.68 & 2.99 & 0.34 \\
\hline
\end{tabular}

Abbreviations: CA Cardiac arrest, CPR Cardiopulmonary resuscitation, NSE Neuron-specific enolase, PEA Pulseless electrical activity, ROSC Return of spontaneous circulation, VF Ventricular fibrillation, VT Ventricular tachycardia

approach and with multiple tests and parameters $[9,30]$. Clearly, NSE outperformed S100 for outcome prediction after CA in the same patient cohort [17]. Adding S100 to our model including clinical characteristics and NSE did not further improve the accuracy of the model. Similar results have also been described by others when $\mathrm{S} 100$ was added to NSE [25]. Using a multivariable model with fewer variables, researchers in another study suggested the usefulness of S100 over NSE on admission [22]. Although the use of a combination of biomarkers for outcome prediction is intriguing, we failed to demonstrate any added value of S100 in a clinical model including NSE.

\section{Limitations and strengths}

Biomarkers are unlikely to be affected by sedation, in contrast to some neurophysiological tests or the clinical examination, and therefore they may be more objective markers of brain injury. However, they are measured intermittently, whereas their production or secretion and metabolism are a dynamic process, underscoring the importance of serial measurements. This study is a predefined substudy of the TTM trial, and we acknowledge any potential limitations of this trial. Not all patients included in the TTM trial participated in the sampling, and not all patients had a sample drawn at each time point. Because of randomization stratified by site, we believe that this did not have a significant influence on the results and that there was no difference between our study cohort and the main TTM trial cohort. We acknowledge that, according to our study protocol, there was no blood sampling on admission or prior to $24 \mathrm{~h}$, which deprived us from analyzing the potential value of very early S100 measurements. Another limitation is that we had no external quality control at the participating sites where samples were collected and preanalytically processed.

The main strength of our study is the large sample size of a predefined substudy of a multicenter clinical trial investigating two target temperatures in comatose patients after OHCA. The TTM trial had strict rules and protocols regarding prognostication and how WLST was conducted [14]. In addition, all the samples were analyzed at a single core laboratory after the completion of the study, ruling out the problem of variation between laboratories and limiting the risk of "self-fulfilling prophecy" due to having bedside access to the biomarkers.

\section{Conclusions}

There was no clinically important effect of two different target temperatures on levels of S100. High S100 values are predictive of poor outcome after OHCA but do not add any real value to present prognostication models with or without NSE. S100 measured at $24 \mathrm{~h}$ and afterward is of limited value in clinical outcome prediction after OHCA, especially in a setting where NSE is available. 


\section{Additional file}

Additional file 1: List of the ethical review boards that accepted the trial and the approval reference numbers. (DOCX $12 \mathrm{~kb}$ )

\section{Abbreviations}

CA: Cardiac arrest; CPC: Cerebral Performance Categories Scale; CPR: Cardiopulmonary resuscitation; FPR: False-positive rate; ICU: Intensive care unit; IDI: Integrated discrimination improvement; NRI: Net Reclassification Index; NSE: Neuron-specific enolase; OHCA: Out-of-hospital cardiac arrest; PEA: Pulseless electrical activity; ROSC: Return of spontaneous circulation; TTM: Target Temperature Management after Out-of-Hospital Cardiac Arrest trial; VF: Ventricular fibrillation; VT: Ventricular tachycardia; WLST: Withdrawal of life-supporting therapies

\section{Acknowledgements}

Samples used in this study were stored and processed at the Integrated BioBank of Luxembourg (IBBL) in compliance with ISO 9001:2008, NF S96-900:2011, and ISO 17025:2005 standards and International Society for Biological and Environmental Repositories (ISBER) Best Practices. We thank Jacqueline Kieffer and the staff of the biochemistry laboratory of the Centre Hospitalier de Luxembourg. We include in our thanks all staff from all the sites involved in the biomarker collection and handling.

\section{Funding}

The TTM trial was funded by independent research grants from the Swedish Heart-Lung Foundation; Arbetsmarknadens försäkringsaktiebolag (AFA) Insurance Foundation; The Swedish Research Council; regional research support, Region Skåne; government funding of clinical research within the Swedish National Health Services; Thelma Zoega Foundation; Krapperup Foundation; Thure Carlsson Foundation; Hans-Gabriel and Alice Trolle-Wachtmeister Foundation for Medical Research; Skåne University Hospital, Sweden; TrygFonden, Denmark; the European Clinical Research Infrastructures Network; the European Critical Care Research Network; the Ministry of Higher Education and Research of Luxembourg; and the National Research Fund, Luxembourg. No commercial funding was received. The funding organizations did not have any access to the data, nor did they have any influence on data analysis or interpretation.

\section{Availability of data and materials}

Data analyzed during the present study are currently stored in the TTM trial database. Their availability is regulated by the authorization of the TTM trial steering committee.

\section{Authors' contributions}

PS, NN, YD, CH, HF, MK, MPW, and DE conceived of this study. NN, HF, CH, and YD obtained funding. GG performed the laboratory analysis. OC designed the statistical analysis. FF performed the statistical analysis. PS, HF, NN, and YD drafted the manuscript. JD, MW, JU, JW, TP, AA, JHov, JHor, TC, $J K$, and $Y G$ are steering committee members who actively recruited patients and participated in blood sampling. All authors read, critically reviewed, and approved the final manuscript.

\section{Competing interests}

TP and HF report receiving lecture fees from Bard Medical. MPW reports serving on an advisory board for Bard Medical. The other authors declare that they have no competing interests.

\section{Ethics approval and consent to participate}

In line with the Helsinki declaration, the TTM trial protocol was approved by ethics committees in each participating country, and informed consent was waived or obtained from all participants or relatives according to national legislation. A list of the ethics committees and the reference of their approval of the trial in each participating country are provided in Additional file 1.

\section{Publisher's Note}

Springer Nature remains neutral with regard to jurisdictional claims in published maps and institutional affiliations.

\section{Author details}

'Department of Anesthesia and Intensive Care Medicine, Centre Hospitalier de Luxembourg, 4, rue Barblé, L-1210 Luxembourg, Luxembourg. ${ }^{2}$ Department of Cardiology, Skåne University Hospital, Lund, Sweden. ${ }^{3}$ Department of Anesthesia and Intensive Care, Helsingborg Hospital, Helsingborg, Sweden. ${ }^{4}$ Competence Centre for Methodology and Statistics, Luxembourg Institute of Health, Strassen, Luxembourg. ${ }^{5}$ Department of Cardiology B, The Heart Centre, Rigshospitalet University Hospital, Copenhagen, Denmark. ${ }^{6}$ Department of Thoracic Anesthesiology, The Heart Centre, Rigshospitalet University Hospital, Copenhagen, Denmark. ${ }^{7}$ Department of Anesthesia and Intensive Care, Hallands Hospital, Lund University, Halmstad, Sweden. ${ }^{8}$ Copenhagen Trial Unit, Centre of Clinical Intervention Research, Rigshospitalet, Copenhagen, Denmark. ${ }^{9}$ Department of Anesthesia and Intensive Care, Azienda Ospedaliera 'Card. G. Panico', Tricase, Italy. ${ }^{10}$ Department of Intensive Care, Liverpool Hospital, Sydney, NSW, Australia. ${ }^{11}$ Department of Anesthesia and Intensive Care, Oslo University Hospital, Rikshospitalet, Oslo, Norway. ${ }^{12}$ Department of Intensive Care, University Hospital of Wales, Cardiff, UK. ${ }^{13}$ Department of Clinical Biology, Centre Hospitalier de Luxembourg, Luxembourg, Luxembourg. ${ }^{14}$ Department of Intensive Care, Academic Medical Centrum, Amsterdam, The Netherlands. ${ }^{15}$ Section of Neurology, Department of Clinical Sciences Lund, Lund University, Skåne University Hospital, Lund, Sweden.

${ }^{16}$ Department of Intensive Care, Leeuwarden Medical Centrum, Leeuwarden, The Netherlands. ${ }^{17}$ Department of Intensive Care, Geneva University Hospital, Geneva, Switzerland. ${ }^{18}$ Cardiovascular Research Unit, Luxembourg Institute of Health, Luxembourg, Luxembourg. ${ }^{19}$ Department of Anesthesia and Intensive Care, Skåne University Hospital, Lund University, Lund, Sweden.

Received: 2 April 2017 Accepted: 22 May 2017

Published online: 20 June 2017

\section{References}

1. Lemiale V, Dumas F, Mongardon N, Giovanetti O, Charpentier J, Chiche JD, et al. Intensive care unit mortality after cardiac arrest: the relative contribution of shock and brain injury in a large cohort. Intensive Care Med. 2013;39(11):1972-80

2. Dragancea I, Rundgren $M$, Englund $E$, Friberg $H$, Cronberg $T$. The influence of induced hypothermia and delayed prognostication on the mode of death after cardiac arrest. Resuscitation. 2013;84(3):337-42.

3. Laver S, Farrow C, Turner D, Nolan J. Mode of death after admission to an intensive care unit following cardiac arrest. Intensive Care Med. 2004;30(11):2126-8.

4. Donato R. Functional roles of $\mathbf{S 1 0 0}$ proteins, calcium-binding proteins of the EF-hand type. Biochim Biophys Acta. 1999;1450(3):191-231.

5. Zimmer DB, Cornwall EH, Landar A, Song W. The S100 protein family: history, function, and expression. Brain Res Bull. 1995;37(4):417-29.

6. Schafer BW, Heizmann CW. The S100 family of EF-hand calcium-binding proteins: functions and pathology. Trends Biochem Sci. 1996;21(4):134-40.

7. Sandroni C, Cavallaro F, Callaway CW, Sanna T, D'Arrigo S, Kuiper M, et al. Predictors of poor neurological outcome in adult comatose survivors of cardiac arrest: a systematic review and meta-analysis. Part 1: Patients not treated with therapeutic hypothermia. Resuscitation. 2013;84(10):1310-23.

8. Sandroni C, Cavallaro F, Callaway CW, D'Arrigo S, Sanna T, Kuiper MA, et al. Predictors of poor neurological outcome in adult comatose survivors of cardiac arrest: a systematic review and meta-analysis. Part 2: Patients treated with therapeutic hypothermia. Resuscitation. 2013;84(10):1324-38.

9. Sandroni C, Cariou A, Cavallaro F, Cronberg T, Friberg H, Hoedemaekers C, et al. Prognostication in comatose survivors of cardiac arrest: an advisory statement from the European Resuscitation Council and the European Society of Intensive Care Medicine. Resuscitation. 2014:85(12):1779-89.

10. Steiner J, Bernstein HG, Bielau H, Berndt A, Brisch R, Mawrin C, et al. Evidence for a wide extra-astrocytic distribution of S100B in human brain. BMC Neurosci. 2007;8:2.

11. Unden J, Bellner J, Eneroth M, Alling C, Ingebrigtsen T, Romner B. Raised serum S100B levels after acute bone fractures without cerebral injury. J Trauma. 2005;58(1):59-61.

12. Unden J, Christensson B, Bellner J, Alling C, Romner B. Serum S100B levels in patients with cerebral and extracerebral infectious disease. Scand J Infect Dis. 2004;36(1):10-3.

13. Nielsen N, Wetterslev J, Cronberg T, Erlinge D, Gasche $Y$, Hassager C, et al. Targeted temperature management at $33{ }^{\circ} \mathrm{C}$ versus $36{ }^{\circ} \mathrm{C}$ after cardiac arrest. N Engl J Med. 2013;369(23):2197-206. 
14. Nielsen N, Wetterslev J, al-Subaie N, Andersson B, Bro-Jeppesen J, Bishop G, et al. Target Temperature Management after out-of-hospital cardiac arrest-a randomized, parallel-group, assessor-blinded clinical trial—rationale and design. Am Heart J. 2012;163(4):541-8.

15. Nielsen N, Winkel P, Cronberg T, Erlinge D, Friberg H, Gasche $Y$, et al. Detailed statistical analysis plan for the target temperature management after out-of-hospital cardiac arrest trial. Trials. 2013;14:300.

16. Jennett B, Bond M. Assessment of outcome after severe brain damage. Lancet. 1975;1(7905):480-4

17. Stammet P, Collignon O, Hassager C, Wise MP, Hovdenes J, Aneman A, et al. Neuron-specific enolase as a predictor of death or poor neurological outcome after out-of-hospital cardiac arrest and targeted temperature management at $33{ }^{\circ} \mathrm{C}$ and $36{ }^{\circ} \mathrm{C}$. J Am Coll Cardiol. 2015;65(19):2104-14.

18. Pfeifer R, Franz M, Figulla HR. Hypothermia after cardiac arrest does not affect serum levels of neuron-specific enolase and protein S-100b. Acta Anaesthesiol Scand. 2014;58(9):1093-100.

19. Tiainen $M$, Roine RO, Pettila $V$, Takkunen O. Serum neuron-specific enolase and S-100B protein in cardiac arrest patients treated with hypothermia. Stroke. 2003;34(12):2881-6.

20. Rundgren $M$, Karlsson $T$, Nielsen $N$, Cronberg $T$, Johnsson P, Friberg $H$. Neuron specific enolase and S-100B as predictors of outcome after cardiac arrest and induced hypothermia. Resuscitation. 2009;80(7):784-9.

21. Stammet $P$, Wagner DR, Gilson G, Devaux Y. Modeling serum level of s100 $\beta$ and bispectral index to predict outcome after cardiac arrest. J Am Coll Cardiol. 2013;62(9):851-8.

22. Einav S, Kaufman N, Algur N, Kark JD. Modeling serum biomarkers S100ß and neuron-specific enolase as predictors of outcome after out-of-hospital cardiac arrest: an aid to clinical decision making. J Am Coll Cardiol. 2012; 60(4):304-11.

23. Bottiger BW, Mobes S, Glatzer R, Bauer H, Gries A, Bartsch P, et al. Astroglial protein S-100 is an early and sensitive marker of hypoxic brain damage and outcome after cardiac arrest in humans. Circulation. 2001;103(22):2694-8.

24. Martens P, Raabe A, Johnsson P. Serum S-100 and neuron-specific enolase for prediction of regaining consciousness after global cerebral ischemia. Stroke. 1998;29(11):2363-6.

25. Larsson IM, Wallin E, Kristofferzon ML, Niessner M, Zetterberg $H$, Rubertsson S. Post-cardiac arrest serum levels of glial fibrillary acidic protein for predicting neurological outcome. Resuscitation. 2014;85(12):1654-61.

26. Shinozaki K, Oda S, Sadahiro T, Nakamura M, Abe R, Nakada TA, et al. Serum $\mathrm{S}-100 \mathrm{~B}$ is superior to neuron-specific enolase as an early prognostic biomarker for neurological outcome following cardiopulmonary resuscitation. Resuscitation. 2009;80(8):870-5.

27. Westaby S, Johnsson P, Parry AJ, Blomqvist S, Solem JO, Alling C, et al. Serum S100 protein: a potential marker for cerebral events during cardiopulmonary bypass. Ann Thorac Surg. 1996;61(1):88-92.

28. Undén J, Ingebrigtsen T, Romner B, Scandinavian Neurotrauma Committee (SNC). Scandinavian guidelines for initial management of minimal, mild and moderate head injuries in adults: an evidence and consensus-based update. BMC Med. 2013;11:50.

29. Zandbergen EG, Hijdra A, Koelman JH, Hart AA, Vos PE, Verbeek MM, et al. Prediction of poor outcome within the first 3 days of postanoxic coma. Neurology. 2006;66(1):62-8

30. Nolan JP, Soar J, Cariou A, Cronberg T, Moulaert VR, Deakin CD, et al. European Resuscitation Council and European Society of Intensive Care Medicine Guidelines for Post-resuscitation Care 2015: Section 5 of the European Resuscitation Council Guidelines for Resuscitation 2015 Resuscitation. 2015;95:202-22.

\section{Submit your next manuscript to BioMed Central and we will help you at every step:}

- We accept pre-submission inquiries

- Our selector tool helps you to find the most relevant journal

- We provide round the clock customer support

- Convenient online submission

- Thorough peer review

- Inclusion in PubMed and all major indexing services

- Maximum visibility for your research

Submit your manuscript at www.biomedcentral.com/submit
Biomed Central 